\section{Subnotificação e (in)visibilidade da violência contra mulheres na atenção primária à saúde}

\author{
Primary healthcare and underreporting and \\ (in)visibility of violence against women
}

Subnotificación e (in)visibilidad de la violencia
contra las mujeres en la atención primaria

a la salud
Luciana Kind 1

Maria de Lourdes Pereira Orsini 2

Valdênia Nepomuceno ${ }^{2}$

Letícia Gonçalves 1

Gislaine Alves de Souza 1

Monique Fernanda Félix Ferreira 1

\footnotetext{
${ }_{1}$ Pontifícia Universidade Católica de Minas Gerais, Belo Horizonte, Brasil. 2 Secretaria Municipal de Saúde de Belo Horizonte, Belo Horizonte, Brasil.

Correspondência L. Kind

Pontificia Universidade Católica de Minas Gerais. Av. Itaú 525, Belo Horizonte, MG 30535-012, Brasil.

lukind@gmail.com
}

\begin{abstract}
This study aimed to map indicators of violence against women as recorded by primary healthcare services in Belo Horizonte, Minas Gerais State, Brazil, and to identify difficulties experienced by health professionals in reporting such violence. Epidemiological data on this type of notification were collected in the information system of the Municipal Health Department. Data were produced with a semi-structured questionnaire and three focus group sessions with participation by 270 primary care professionals. The data were submitted to content analysis and were coded, categorized, and discussed in light of a literature review. A central analytical axis was called (in)visibility of violence against women. The data revealed both the recognition of violence as a public health problem and the invisibility that prevents dealing with it properly. Notification of such violence is often viewed as a fuss or commotion, which hampers progress in discussing and acting on the problem.
\end{abstract}

Notice; Violence Against Women; Health Personnel; Primary Heath Care

\section{Resumo}

Esta pesquisa teve por objetivo mapear indicadores de violências contra mulheres em unidades básicas de saúde de Belo Horizonte, Minas Gerais, Brasil, e identificar as dificuldades experimentadas por profissionais de saúde na notificação de violências. Dados epidemiológicos sobre esse tipo de notificação foram levantados no sistema de informações da Secretaria Municipal de Saúde. Dados qualitativos foram produzidos com questionário semiestruturado e três sessões de grupos focais, com a participação de 270 profissionais da atenção primária à saúde. Os dados foram submetidos à análise de conteúdo, sendo codificados, categorizados e discutidos à luz da revisão de literatura. Um eixo analítico central foi denominado (in)visibilidade da violência contra mulheres. Emergem dos dados tanto o reconhecimento da violência como problema de saúde pública quanto a invisibilidade que impede o seu enfrentamento. Observa-se que a notificação é frequentemente tomada como denúncia, o que dificulta o avanço nas discussões e ações concernentes ao problema.

Notificação; Violência Contra a Mulher; Pessoal de Saúde; Atenção Primária à Saúde 
A violência contra mulheres tem sido sistematicamente pautada pela agenda das políticas públicas de saúde desde os anos 1990, em decorrência de consensos internacionais de sua crescente relevância como problema de saúde pública 1,2,3. A despeito disso, a procura de mulheres por serviços de saúde com efeitos diretos de agressões, "queixas vagas" ou mesmo "invisíveis" que sugerem situações de violência nem sempre é abordada diretamente, conferindo à violência contra mulheres a condição de um problema "velado" 3,4,5. Essa "invisibilidade" da violência se insinua nos serviços de saúde, que se restringem, na maioria das vezes, a tratar os efeitos das violências vividas por mulheres 4 .

Alguns autores assinalam ser comum que os profissionais sintam-se impotentes diante de situações de assistência a mulheres em situação de violência 5,6,7,8,9,10. Nesses estudos, são ressaltadas as percepções de diferentes profissionais marcadas por estereótipos de gênero que naturalizam o homem como agressivo e violento e a mulher como passiva e vítima. Essas investigações colocam em questão o descompasso entre as percepções dos profissionais e as diretrizes das políticas públicas para as mulheres em sua interface com a saúde pública. Na prática dos profissionais de saúde, por motivos diversificados, a violência contra mulheres nem sempre é tomada, em si mesma, como questão de saúde pública. A literatura sugere, ainda, que a própria formação profissional não aborda esse problema como questão de saúde pública 10,11.

São recentes as iniciativas de registro da violência em sistemas específicos de informação em saúde 12,13. No Brasil, o Sistema de Informações sobre Mortalidade (SIM) revela que o número de óbitos por violência apresenta taxas de crescimento significativas, porém, alguns autores apontam para as limitações desse sistema na identificação precisa das situações de violência contra mulheres 13. Atualmente, os dados sobre a violência contra mulheres no âmbito da saúde são registrados no Sistema de Informações sobre Agravos de Notificação (SINAN), via Ficha de Notificação para Violência Doméstica, Sexual e/ou outras Violências (Secretaria de Vigilância à Saúde, Ministério da Saúde. Ficha de notificação de violência doméstica, sexual e/ou outras violências interpessoais. http://bvsms.saude.gov.br/ bvs/folder/ficha_notificacao_violencia_domes tica.pdf, acessado em 06/Set/2010). Enquanto o SIM apresenta maiores taxas de violência entre homens, o SINAN reflete a soberania de agressões contra mulheres, principalmente na faixa etária de 20 a 59 anos 14,15.

A Lei no 10.778 de 200316 estabelece, em âmbito nacional, a notificação compulsória nos atendimentos realizados em serviços de saúde, públicos ou privados, nos casos de violência contra mulheres. Contudo, os indicadores de saúde ainda parecem escassos quando se trata desse problema, dificultando-se a produção de estatísticas sistematizadas sobre esse agravo ${ }^{17}$. Apenas em 2010 o Município de Belo Horizonte, Minas Gerais, aderiu ao Pacto Nacional de Enfrentamento à Violência Contra a Mulher, firmando-se a meta de "implementar a Notificação Compulsória da Violência nas 147 Unidades Básicas de Saúde (UBS), nas oito Unidades de Pronto Atendimento do município e na rede conveniada" 18.

As estratégias de registro de informações, por mais que careçam de aprimoramentos, pretendem contribuir para gerar dados que dimensionem a magnitude da violência contra mulheres como questão a ser enfrentada por diferentes setores e categorias profissionais 12,13. Contudo, elas não são canais exclusivos de visibilidade desse fenômeno. Pesquisas qualitativas, com diferentes enfoques, também contribuem para sua desnaturalização, além de atestarem sua relevância para se pensar estratégias de enfrentamento da violência contra mulheres 4,5,7,8,10,19.

Considerando-se o contexto traçado, este trabalho tem o propósito de compartilhar os dados mais significativos de uma pesquisa realizada em Belo Horizonte, envolvendo profissionais da atenção primária à saúde lotados no Distrito Sanitário Nordeste (DISANE). A investigação teve origem em um convênio entre a Secretaria $\mathrm{Mu}$ nicipal de Saúde de Belo Horizonte e o projeto da Pontifícia Universidade Católica de Minas Gerais (PUC Minas) para o Programa Nacional de Reorientação da Formação Profissional em Saúde (Pró-Saúde). No desdobramento desse convênio, a pesquisa derivou-se das ações do Programa de Educação pelo Trabalho para Saúde (PET-Saúde) na PUC Minas. A equipe que a desenvolveu foi composta por profissionais e graduandas de diferentes cursos, a saber: psicologia, nutrição, farmácia, enfermagem, odontologia, fisioterapia e fonoaudiologia. O objetivo central era mapear indicadores de violência contra mulheres do DISANE, pretendendo compreender como a notificação tem sido realizada nos serviços e situar as principais dificuldades experimentadas pelos profissionais de saúde para efetivá-la.

\section{Metodologia}

A pesquisa teve um desenho quantiqualitativo, foi desenvolvida em diferentes momentos, guiada pela triangulação metodológica 20 como forma de diversificar as possibilidades de olhar para o imbricado fenômeno estudado. Ampa- 
ramo-nos para isso, em discussões metodológicas preocupadas com os contornos gerais da produção de dados empíricos 21,22,23. Também foram consultados textos de apoio à construção das estratégias específicas de coleta e análise dos dados $24,25,26,27$.

Todas as fases de coleta foram desenvolvidas em diálogo com a Gerência Distrital, a Gerência de Gestão do Trabalho (GERGETR-NE), a Gerência de Regulação, Epidemiologia e Informação do DISANE (GEREPI-NE) e as gerências de Centros de Saúde. O território do DISANE comporta 21 UBS com um quadro funcional composto por aproximadamente 320 profissionais de nível superior lotados em equipes de assistência à saúde da população adscrita. Esses dados foram informados pela GERGETR-NE, que revelou-nos a dificuldade de se precisar o contingente exato de profissionais na atenção primária à saúde em decorrência da alta rotatividade nos postos de trabalho e dos constantes afastamentos e licenças solicitados pelos profissionais.

A primeira fase, a aplicação dos questionários, foi realizada entre janeiro e abril de 2011. O instrumento foi elaborado pela equipe, contendo seis questões fechadas e quatro abertas, contemplando-se informações sobre formação profissional, tempo de trabalho e conhecimento dos documentos e equipamentos relacionados à violência contra mulheres. Todos os profissionais de saúde que integram as equipes de saúde da família (ESF), saúde mental, saúde bucal, profissionais de apoio e Núcleo de Apoio à Saúde da Família (NASF) do DISANE foram convidados a participar do estudo. As entradas em campo foram antecedidas por contatos com os gerentes de cada UBS para apresentação da pesquisa. Em seguida, os profissionais eram diretamente convidados a participar, preenchendo o questionário em seus locais de trabalho. Do total estimado, 270 profissionais responderam ao questionário. Houve pouca recusa direta, sendo mais habitual a justificativa de falta de tempo para se dedicar ao questionário. Essa fase de coleta foi registrada em diários de campo.

A segunda fase compreendeu a realização de três grupos focais no mês de junho de 2011, envolvendo um total de 32 trabalhadores. Foram convidados profissionais de diferentes categorias e UBS que haviam respondido afirmativamente à última questão do questionário sobre o interesse em participar de um grupo focal com o tema notificação de violência contra mulheres.

A terceira fase constituiu no levantamento de dados sobre violência contra mulheres registrados nos sistemas de informação com os quais o DISANE opera. Em momentos distintos de desenvolvimento da pesquisa a GEREPI-NE foi contatada para apresentação dos objetivos e coelaboração de uma demanda mais precisa sobre os dados que seriam necessários para o estudo. A GEREPI-NE organizou as informações em forma de gráficos, tabelas e planilhas, que foram apresentadas e disponibilizadas para a equipe.

O tratamento do conjunto dos dados desta pesquisa gerou diferentes unidades de análise (gráficos, tabelas, planilhas, categorias, subcategorias e respectivas unidades de registro). Combinadas e aproximadas, essas unidades de análise permitiram a construção de um panorama multifacetado dos dados epidemiológicos relacionados à violência contra mulheres e das percepções dos profissionais de saúde sobre a notificação em seu contexto de atuação. Este artigo focaliza algumas informações compartilhadas pela GEREPI-NE e a análise de conteúdo dos dados qualitativos gerados nas respostas abertas do questionário e nas discussões oriundas dos grupos focais. O detalhamento dos demais dados produzidos será alvo de outro texto.

As transcrições das questões abertas do questionário e dos grupos focais foram submetidas à análise de conteúdo 27 . Como ferramenta de apoio à análise de conteúdo, utilizou-se o software ATLAS.ti, versão 6.0 (Scientific Software Development GmbH, Berlim, Alemanha). A codificação do material com essa ferramenta de suporte à análise de dados qualitativos gera citações, códigos, famílias de códigos 28 que, quando guiada pela análise de conteúdo, corresponde a unidades de registro, subcategorias e categorias, respectivamente.

Para se manter as identidades dos participantes em sigilo, as citações que aparecerão ao longo do texto mantêm as siglas e números utilizados durante os registros: CS para "centros de saúde", seguidos de números entre 1 e 21; S para "sujeito", seguido de números entre 1 e 270 . As categorias profissionais e sexo de cada um deles também compõem essa nomeação fictícia dos sujeitos. Nos casos em que a categoria não permite flexão de gênero, optamos por acrescentar "f" ou "m" (para feminino ou masculino) como complemento da codificação.

A pesquisa foi aprovada pelo Comitê de Ética em Pesquisa da Secretaria Municipal de Saúde de Belo Horizonte - parecer no 0221.0.213.410-10A -, observando-se, em seu desenvolvimento, os preceitos éticos previstos na Resolução no 196/96 do Conselho Nacional de Saúde.

\section{Resultados}

Os dados levantados em diálogo com a GEREPINE confirmam a hipótese de subnotificação da 
violência contra mulheres. A Tabela 1 explicita o número de notificações realizadas nos nove Distritos Sanitários de Belo Horizonte. Os dados relativos ao DISANE estão destacados, mostrando o baixo índice de notificações realizadas neste distrito. Cabe acentuar que os distritos com maior número de notificações, considerando-se o total de registros entre 2001 e 2011 (notadamente Noroeste e Centro-sul), contam com hospitais e serviços especializados no acolhimento de casos de violência.

Também se percebe o crescimento gradativo de notificações por ano, cujos registros se intensificam a partir de 2006, ano de promulgação da Lei Maria da Penha 29.

Quanto às notificações relacionadas a usuárias adscritas ao território do DISANE, observase baixo número de registros feitos em UBS. A Tabela 2 organiza em ordem decrescente os equipamentos de saúde que realizaram a notificação de violência contra mulheres entre 2001 e 2011. Apenas 14 dos 21 centros de saúde a tinham realizado. De qualquer maneira, destaca-se que o Centro de Saúde Gentil Gomes realizou sete notificações nesse período, indicando alguma mobilização da unidade em torno da questão das violências.

No processo de análise dos dados das questões abertas dos questionários e dos três grupos focais emergem percepções diversificadas sobre o tema da violência contra mulheres e posicionamentos frente à notificação. Dos resultados da análise dos dados qualitativos, foco deste artigo, as categorias mais significativas foram: invisibilidade da violência contra mulheres; visibilidade da violência contra mulheres; por que não notificar? Algumas subcategorias foram mantidas sem conexões diretas com as categorias gerais, por acentuarem aspectos mais específicos que devem, a nosso ver, ser ressaltados. São elas: desconhecimento dos profissionais e notificação como denúncia.

\section{A (in)visibilidade da violência contra mulheres}

Duas categorias foram aproximadas pelo contraste dos dados que revelam, permitindo a construção de um eixo analítico elucidativo da ambiguidade experimentada na atuação profissional na atenção primária à saúde que se depara cotidianamente com a violência contra mulheres. Como síntese da aproximação dessas categorias, produziu-se um eixo analítico central denominado (in)visibilidade da violência contra mulheres. Nesse eixo, são condensadas subcategorias que ora marcam a visibilidade, ora a invisibilidade da violência contra mulheres, além de assinalar subcategorias compostas de unidades de significação que revelam posicionamentos fronteiriços entre expor e ocultar a violência contra mulheres.

A categoria invisibilidade da violência contra mulheres é composta por subcategorias que demonstram certa recusa em reconhecer este tipo de violência como algo que aparece com grande frequência na atenção primária à saúde. Alguns recortes dos dados demonstram que esse problema é sistematicamente colocado "fora do alcance dos olhos".

Notificações de violência doméstica, sexual e/ou outras violências por Distrito Sanitário de atendimento. Belo Horizonte, Minas Gerais, Brasil, $2001-2011$.

\begin{tabular}{|c|c|c|c|c|c|c|c|c|c|c|c|c|}
\hline Distrito Sanitário & 2001 & 2002 & 2003 & 2004 & 2005 & 2006 & 2007 & 2008 & 2009 & 2010 & 2011 & $\begin{array}{r}\text { Total po } \\
\text { distrito }\end{array}$ \\
\hline Centro-sul & 1 & & & & & 42 & 106 & 84 & 141 & 117 & 47 & 538 \\
\hline Leste & & & & & & 4 & 14 & 11 & 9 & 50 & 54 & 142 \\
\hline Nordeste & & & & & 1 & & 2 & 10 & 14 & 5 & 12 & 44 \\
\hline Noroeste & & & & 1 & & 81 & 167 & 123 & 105 & 49 & 72 & 598 \\
\hline Norte & & & & & & & 4 & 9 & 9 & 10 & 7 & 39 \\
\hline Oeste & & & & & & & 11 & 13 & 64 & 62 & 29 & 179 \\
\hline Pampulha & & & & & & & & 4 & 9 & 10 & 18 & 41 \\
\hline Venda Nova & & & & & & & & & 31 & 10 & 8 & 49 \\
\hline Outros municípios & & & & & & & & & 2 & & & 2 \\
\hline Total geral & 1 & 0 & 1 & 3 & 1 & 135 & 367 & 330 & 525 & 516 & 503 & \\
\hline
\end{tabular}


Notificações de violência doméstica, sexual e/ou outras violências contra mulheres por unidade da primeira notificação. Regional Nordeste, Belo Horizonte, Minas Gerais, Brasil, 2001-2011.

\begin{tabular}{|c|c|}
\hline Unidade notificadora & $\mathrm{n}$ \\
\hline Hospital Municipal Odilon Behrens & 144 \\
\hline Maternidade Odete Valadares & 32 \\
\hline Hospital das Clínicas da UFMG & 12 \\
\hline UPA Norte & 7 \\
\hline Centro de Saúde Gentil Gomes & 7 \\
\hline Hospital João XXIII & 4 \\
\hline Centro de Saúde Alcides Lins & 4 \\
\hline Centro de Saúde Olavo Albino Correia & 3 \\
\hline Centro de Saúde Marcelo Pontel & 3 \\
\hline Centro de Saúde Conjunto Paulo VI & 3 \\
\hline UPA Leste & 2 \\
\hline Hospital São Camilo & 2 \\
\hline Hospital Júlia Kubitschek & 2 \\
\hline Centro de Saúde Vila Maria & 2 \\
\hline Centro de Saúde Leopoldo Crisóstomo & 2 \\
\hline Centro de Saúde Goiânia & 2 \\
\hline Centro de Saúde São Marcos & 1 \\
\hline Centro de Saúde São Gabriel & 1 \\
\hline Centro de Saúde Ribeiro de Abreu & 1 \\
\hline Centro de Saúde Nazaré & 1 \\
\hline Centro de Saúde Mariano de Abreu & 1 \\
\hline Centro de Saúde Efigênia Murta & 1 \\
\hline Centro de Saúde Capitão Eduardo & 1 \\
\hline Total & 238 \\
\hline
\end{tabular}

A sexta pergunta do questionário era assim enunciada: "Qual é a sua opinião sobre a notificação compulsória de violências contra mulheres?". Essa indagação suscitou alta frequência da expressão "nunca notifiquei". A subnotificação, termo que nomeia uma das subcategorias, é explicitada em algumas citações semelhantes à seguinte:

CS14 S69 Médica: “...eu acho que às vezes fica muito subdiagnosticado, subnotificado, vamos dizer assim. Falar que não está tendo violência, o pessoal está achando que não tem notificação, então não tem políticas públicas pra isso. Então eu acho que realmente seria importantíssimo a gente notificar" (Grupo focal 2).

Um elemento importante que contribui para certa "invisibilidade" da violência contra mulheres se expressa em algumas afirmações encontradas em diferentes momentos da produção de dados. O código in vivo - ou seja, uma subcategoria que foi nomeada exatamente como um dos sujeitos expressou em um fragmento de dado - "não atendo casos de violência" expressa de modo direto o não reconhecimento da violência contra mulheres como parte do cotidiano das ações de alguns profissionais de saúde. Concentram-se nessa subcategoria as falas de pediatras e cirurgiões-dentistas, algumas em que se alega explicitamente o não atendimento direto de mulheres em situação de violência como fator que o protege de "ver" os vestígios deste problema. Profissionais de outras categorias relatam o pouco tempo de atuação como um dos fatores de não terem contato com esse tipo de problema.

CS18 S16 Enfermeira: "Não tenho experiência nessa área. Estou atuando há apenas 1 mês na unidade" (Questionário; questão 7).

CS6 S231 Psicóloga: “...é um período muito curto esse meu trabalho... o que eu conheço dos centros de saúde. Isso não chega para mim, não tem chegado, nem nos matriciamentos" (Grupo focal 1).

Dentre as subcategorias que se atrelam à $v i$ sibilidade da violência contra mulheres, as denominadas estímulo à formalização da denúncia $\mathrm{e}$ notificação como monitoramento e subsídio de políticas públicas são emblemáticas de posicionamentos favoráveis a se "fazer ver" a violência contra mulheres. A primeira agremia citações que convocam à coibição da violência, principalmente nas respostas escritas no questionário referentes à questão 8 ("Qual é sua opinião sobre a violência contra mulheres?”) e à questão 9 ("Que orientações você daria ou costuma dar a mulheres em situação de violência?"):

CS1 S1 Enfermeira: "Geralmente, incentivo as mulheres a realizar denúncia, ou registrar $B O$ na delegacia especializada para este fim" (Questionário; questão 9).

A notificação como instrumento que fomenta a construção de políticas públicas de enfrentamento à violência contra mulheres é defendida preponderantemente por médicos, enfermeiros e assistentes sociais, ainda que apareça de modo mais isolado na fala de outros profissionais.

No eixo analítico (in)visibilidades da violência contra mulheres, há subcategorias híbridas, assim consideradas por sua dupla face. Por um lado, se reconhece a presença da violência contra mulheres no cotidiano de trabalho na atenção primária à saúde, por outro, há certo silenciamento diante do problema. A dupla "visibilidade/silenciamento" aparece nas subcategorias banalização da violência contra mulheres e violência contra mulheres como algo velado. O caráter "banal” da violência é sumarizada na citação seguinte:

CS9 S32 Cirurgiã-dentista: "Penso ser importante a notificação, mas às vezes deixamos que os 
fatos se tornem corriqueiros; chegamos ao ponto de banalizar os fatos, acreditando fazer parte do cotidiano" (Questionário; questão 6).

A segunda subcategoria relacionada a esse "ver/silenciar-se", comporta expressões sobre o constrangimento diante das situações de violência contra mulheres. Variadas justificativas são apresentadas pelos profissionais de distintas categorias. A idiossincrasia da categoria profissional, as dificuldades de preenchimento da ficha e o fato de as usuárias não quererem falar sobre o assunto são exemplos dessa postura de "não interferência”, para usar a expressão literal de um dos profissionais:

CS3 S190 Cirurgiã-dentista: "Na odontologia não há procura por atendimento de apoio à agredida, sendo constrangedor a interferência no caso" (Questionário; questão 7).

CS6 S241 Médica: “...se existisse um lugar onde ficasse restrito a esse atendimento seria mais interessante, eu acho que teria mais valor o preenchimento dessa ficha. (...) Eu tenho vergonha de perguntar muitas das coisas que estão escritas" (Grupo focal 3).

Motivos para não notificar situações de violência contra mulheres

Outra categoria importante para a compreensão da (in)visibilidade da violência contra mulheres é a nomeada: por que não notificar? Nela, são condensadas subcategorias que trazem de modo explícito os motivos alegados para não se realizar a notificação. Uma das razões centrais produtoras de constrangimento para os profissionais é o medo de retaliação. A essa subcategoria se vinculam unidades de registro que falam dos efeitos da visibilidade da violência tanto para as usuárias quanto para os profissionais.

CS11 S59 Enfermeira: “...eu acho que a equipe fica com certo medo de entrar nos casos, sabe? $E$ durante esse tempo todo, de experiência é... assim, a gente só intervém quando a mulher já chega lá com isso na cara da gente e não tem como você fingir que não viu" (Grupo focal 2).

Como resposta à questão 7 do questionário ("Quais dificuldades você identifica para a realização da notificação?”), o medo de exposição emerge com frequência.

CS5 S216 Profissional de educação física (f): “Acredito que a maior dificuldade é a atuação pósnotificação do profissional, que passa a correr ris$\cos$ [agressões verbais e físicas], atrapalhando assim seu rendimento" (Questionário; questão 7).

CS15 S43 Médico: "Os profissionais de saúde na UBS estão expostos ao agressor, sem os instrumentos de defesa que a própria agredida tem" (Questionário; questão 7).
Mesmo reconhecendo o papel de "diagnóstico da realidade" da ficha, observa-se o constrangimento provocado por seu preenchimento:

CS11 S54 Médica: “É, mas aqui pede muito detalhe. Você identifica [a] mulher com facilidade com essa ficha. Se fosse só uma coisa assim pra política, então vamos fazer uma ficha mais simples" (Grupo focal 2).

Também associada à categoria por que não notificar?, encontra-se a subcategoria notificação dificultada pelo modo de organização do serviço e da assistência. Nas falas dos sujeitos a organização do serviço esconde um possível desconhecimento da notificação, sua importância e obrigatoriedade. $\mathrm{O}$ argumento mais frequentemente exposto nessa subcategoria é o tempo sempre escasso nos processos de trabalho.

CS6 S233 Enfermeira: “Ainda não precisei fazer a notificação, mas se a mulher chegar ao serviço com esta demanda, terá dificuldade em decorrência das agendas que estão sempre preenchidas com consultas, atividades, dentre outras" (Questionário; questão 7).

O fato de o profissional ter contato direto com toda a família, incluindo o agressor, dificulta a notificação. As especificidades da clínica odontológica e a porta aberta para todos os problemas sociais são explicitados como dificultadores de uma conversa mais particularizada com mulheres em situação de violência.

CS6 S241 Médica: “...se a gente lê aquele papel de violência é engraçado assim tem muita coisa intima para responder (...) muitas vezes a gente manda incompleto, porque a paciente não fala para você e não tem como falar aquilo para você e então acho que expõe muito a vida da paciente aquela ficha de notificação, e tem que ser feito em várias vias para ser enviadas, você vai repassar aquilo ali para outras pessoas, acho bastante complicado" (Grupo focal 3).

Grifa-se no último excerto o preenchimento incompleto da ficha, presente nas falas de outros profissionais. Nos contatos com a GEREPI-NE observamos esse elemento como um dos problemas para a produção de dados mais detalhados sobre a violência contra mulheres.

Outro tipo de problematização que emerge dos dados é a comparação entre diferentes tipos de notificação compulsória, com os quais os trabalhadores já se habituaram em suas práticas cotidianas. Nesses casos, indaga-se sobre os desdobramentos que uma notificação de violência contra mulheres teria no âmbito das ações de saúde, sintetizados na fala de uma enfermeira:

S11 S59 Enfermeira: "Pensando no caso da dengue e da tuberculose eu fico pensando nessa ficha de violência assim também do acompanha- 
mento, não na questão da denúncia. Se eu faço uma notificação de uma suspeita de dengue, eu vou acompanhar esse paciente, o distrito vai voltar ele pra mim (...). Como se daria esse acompanhamento na sequência, pra gente saber, a partir dessa ficha de notificação compulsória da violência?" (Grupo focal 2).

Sobre a notificação da violência contra mulheres, é frequente a presença de comentários dos profissionais que alegam desconhecer a ficha. Em alguns casos, fica expresso que o primeiro informe sobre a existência desse instrumento foi a própria pesquisa.

CS12 S88 Médico: "Olha essa notificação eu descobri ela depois que vocês foram lá aplicar o questionário. Depois disto eu já recebi duas notificações" (Grupo focal 2).

A sequência de falas do grupo focal 2 chama a atenção pelo desconhecimento assumido por uma médica para, logo adiante, se dar conta do caráter compulsório da notificação.

CS14 S69 Médica: "Eu desconheço essa ficha. Não conheço".

CS14 S65 Cirurgiã-dentista: "Eu sei que existe, mas nunca preenchi, nunca manuseei”.

CS7 S250 Enfermeira: "Eu nem sabia”.

CS11 S54 Médica: "A mulher que chega disposta a ir até o final, ela deixa você preencher, se ela não quer, ela te conta como um desabafo, mas ela não deixa".

CS14 S69 Médica: "Mas gente, se é uma coisa compulsória, não tem que deixar. Se é compulsória você tem que preencher, não tem que nem falar com ela".

\section{Notificação tomada como denúncia}

Uma categoria instigante produzida no processo de análise foi nomeada notificação como denúncia. Desde as primeiras abordagens analíticas dos dados, começou-se a observar certo atrelamento entre notificação e denúncia, assinalando-se falas em que uma era tomada como sinônimo da outra. De certo modo, esse uso intercambiável dos termos notificação e denúncia, revela um desconhecimento mais profundo da notificação, que vai além da simples falta de acesso à ficha como a subcategoria apresentada anteriormente registra. Perde-se de vista a finalidade da notificação como peça de organização de dados epidemiológicos, de produção de informações de saúde, com vistas ao dimensionamento da magnitude de um dado problema para um planejamento mais adequado de estratégias assistenciais.

CS15 S178 Enfermeira: "Apesar de não conhecer a fich a acredito ser um documento importante na denúncia do ato" (Questionário; questão 6).
CS17 S126 Enfermeira: "O principal motivo da não notificação acredito que seja o medo de violência do agressor, já que o trabalhador de saúde é a referência da denúncia" (Questionário; questão 7).

CS8 S265 Enfermeira: "Na verdade assim, quando você faz uma notificação, soa pra gente como uma denúncia mesmo, e aí você não quer se envolver. Na verdade a gente pode até tá negando isso, eu falo por mim, é como se eu estivesse negando a me envolver" (Grupo focal 1).

Em alguns excertos a mulher é colocada como aquela que realiza a notificação, agudizandose essa substituição sem ressalvas de denúncia por notificação e vice-versa.

CS1 S6 Cirurgiã-dentista: “Às vezes a própria mulher por se encontrar dependente do seu violentador, não notifica, ou quando o faz às vezes volta atrás" (Questionário; questão 7).

Aparecem ainda falas problematizadoras, que não apenas marcam a diferença entre notificação e denúncia, mas exprimem ponderações sobre os efeitos de denúncia que a notificação teria. Não se toma notificação e denúncia como equivalentes, mas alude-se à relação entre os dois tipos de registro.

CS6 S235 Assistente social (f): “[a notificação] deveria ser obrigatória para todos os profissionais que atendem. Deveria ser imposta para todos os profissionais. A notificação compulsória não deveria ser destinada somente para a notificação, mas também para a denúncia. Há pouca resolutividade para os encaminhamentos" (Questionário; questão 6).

As observações feitas pela assistente social colocam em questão o tom de palavra de ordem que geralmente se endereça aos trabalhadores de saúde para o tema: "violência contra mulheres é uma questão de saúde pública”. A profissional reforça a natureza compulsória desse tipo de notificação, convocando os profissionais de saúde para uma postura mais próxima da denúncia, ou seja, de dar maior visibilidade à questão.

\section{Discussões}

Atualmente, na saúde, preconiza-se a utilização de dados concretos para analisar, planejar e tomar decisões pertinentes com as condições de saúde de uma determinada localidade. Para tal, lança-se mão dos sistemas de informações que são vistos como ferramentas indispensáveis para a gestão de políticas públicas 30 . O SINAN fornece informações para a análise do perfil da morbidade e viabiliza um panorama das condições de saúde, nos níveis municipal, estadual e federal 31. O sistema é alimentado, principal- 
mente, pela notificação e investigação de casos de doenças e agravos que constam da lista nacional de notificação compulsória. Para os casos de violência contra mulheres atendidas nos serviços de saúde, imprime-se o caráter sigiloso. Em documento de orientação para práticas de enfrentamento 18 , afirma-se que a identificação da pessoa em situação de violência fora do âmbito dos serviços de saúde somente poderá ocorrer em caráter excepcional, nos casos de risco à comunidade ou à vítima.

A despeito das promessas de sistematização das informações e de maior compreensão de onde e como ocorrem as situações de violência, os profissionais da atenção primária à saúde operam em seu cotidiano de trabalho com outros elementos. A organização da atenção primária à saúde, a sobrecarga de trabalho, o efeito de denúncia, a dimensão técnica das categorias profissionais, a desarticulação entre equipamentos de saúde e serviços de outros setores, se engendram em diferentes conexões entre discursos, práticas, regulamentos, crenças e uma série de outros componentes que são agenciados em torno da notificação da violência contra mulheres.

Diante dos resultados aqui apresentados, analisar a notificação da violência na atenção primária à saúde permite-nos compreender que elementos muito concretos são trazidos para a composição de como os profissionais percebem o problema. A Ficha de Notificação, os dados epidemiológicos, as leis, as formações recebidas pelos diferentes trabalhadores, o cotidiano do trabalho, as usuárias, os agressores, dentre outros, são componentes importantes das múltiplas montagens que são explicitadas nos dados. O eixo (in)visibilidade da violência contra mulheres, ao contrário de indicar uma polaridade entre profissionais que notificam e aqueles que não notificam a violência, mostra que este é um tema que mobiliza posicionamentos diversificados. Ser "favorável" à notificação, posicionamento presente em subcategorias que dão visibilidade à violência contra mulheres, não implica evidências numéricas de notificações, como se vê nos dados epidemiológicos.

Outro ponto que merece nossa atenção é que a compulsoriedade não é garantia, por si só, de aumento das notificações, nem mesmo a subnotificação pode ser pensada como indicadora de que os profissionais não se preocupam com a violência contra mulheres. Mesmo daqueles profissionais que dizem não atender a casos de violência não podemos deduzir que neguem a existência do problema. A reestruturação da atenção primária à saúde colocada em curso com a Estratégia Saúde da Família, aposta no vínculo com a população e entrelaça o cotidiano dos su- jeitos com as práticas de saúde, abrindo aos profissionais problemas diversificados 32,33. Dentre essa diversidade de questões que se apresentam aos profissionais da atenção primária à saúde, a violência contra mulheres exige ações para além da saúde, convocando pactuações intersetoriais. O desconhecimento que se mostra nos resultados desta pesquisa alerta para as dificuldades de mapeamento efetivo de equipamentos de outros setores voltados para o enfretamento da violência contra mulheres. De qualquer modo, esse é também um problema a ser enfrentado no cotidiano dos serviços da atenção primária à saúde e não apenas no nível especializado de assistência à saúde.

Desde o século XVIII, as estratégias biopolíticas de controle da população se preocupam com os índices que revelam problemas para intervenção estatal 34,35. Com outras implicações, que não cabe a este artigo analisar em detalhe, os sistemas atuais de informação em saúde se expandem, mas nem sempre sua função de dar visibilidade a problemas a serem enfrentados resultam em ações específicas. Investe-se em seu potencial de oferecer um diagnóstico adequado dos problemas de saúde, de modo a angariar políticas públicas para enfrentá-los. Entretanto, no caso da violência contra mulheres, a subnotificação, aliada aos dados qualitativos levantados nesta e em outras pesquisas 5,8,10,36,37, deveriam ser suficientes para chamar a atenção do poder público. Como um indicador do que "não pode ser visto" a subnotificação é preocupante, mas evidencia menos a capacidade técnica dos profissionais do que temores, receios, incompreensões e atravessamentos de toda ordem que os interpelam quando confrontados com as violências contra mulheres. Defende-se, portanto, que a subnotificação seja interpretada não como um conjunto de dados ocultos que precisam ser forçados a se revelar. Ao contrário, como mostra este e outros estudos, a notificação (ou não) da violência não resolve os dilemas que perpassam a atuação profissional em saúde na atenção primária à saúde. Infelizmente, os sistemas de informação, e a dimensão numérica dos problemas que eles desenham, são hipervalorizados, em detrimento do acúmulo de conhecimento já produzido em pesquisas qualitativas sobre o tema em análise.

De maneira semelhante ao que encontramos no cenário investigado, outras pesquisas apontam que, embora os profissionais tenham a obrigação de notificar, eles se sentem inábeis frente aos casos de violência doméstica 30,36. Além de afirmações quanto ao desconhecimento da Ficha de Notificação, há profissionais que questionam a obrigatoriedade de se notificar a violência 
contra mulheres. Nesse caso, alguns profissionais a veem como uma denúncia ou alegam ter dúvidas quanto aos desdobramentos que uma notificação de violência contra mulheres teria no âmbito das ações de saúde. Entretanto, também há profissionais que afirmam que a notificação é um instrumento compulsório para construção de dados epidemiológicos para subsidiar políticas públicas.

Observa-se que quando a violência aparece nos dados, são levantadas justificativas para a não notificação: medo de retaliações, dificuldade ou constrangimentos de preencher a Ficha, sobrecarga no cotidiano do serviço e dificuldade em lidar com os casos. A impotência dos profissionais diante dos casos é algo abordado em outros estudos 5,6. Os multifacetados argumentos dos profissionais possibilitam compreender melhor os elementos que atravessam o processo de notificação da violência contra mulheres na atenção primária à saúde, mas jogam luz, de modo especial, nas dificuldades em lidar com esse complexo problema que perpassa suas práticas.

\section{Considerações finais}

A violência contra mulheres é uma realidade do cotidiano dos serviços de saúde da atenção primária e tem sido subnotificada pelos profissionais de saúde. Verifica-se a dimensão plural dos motivos para que a subnotificação seja o dado possível quando se trata de violência contra mulheres, embora não seja o único elemento para se pensar indicadores dessa questão no campo da atenção primária à saúde. Reivindica-se que este e outros estudos - por se dedicarem a apresentar os dilemas e atravessamentos experimentados por profissionais diante da violência contra mulheres em seu cotidiano de trabalho - sejam tomados como trabalhos importantes para motivar ações de enfrentamento desta violência. Tomar a subnotificação como elemento de culpabilização dos profissionais, seria o pior caminho para construção de inteligibilidade para as situações experimentadas no cotidiano dos serviços com relação às violências. Aguardar por um número aceitável de notificação para acionar ações de enfrentamento, significa negligenciar que o "não-número" é também revelador de um problema extremamente complexo.

Os argumentos da compulsoriedade e da produção de indicadores por meio do preenchimento da Ficha de Notificação são insuficientes para que a notificação da violência contra mulheres seja acolhida como instrumento que faz parte do cotidiano das práticas de saúde na atenção primária. Nesta pesquisa, há dados que demonstram o desconhecimento dos profissionais sobre a notificação e sobre que ações devem ser conduzidas para o enfrentamento da violência contra mulheres. Ao lado desses, as falas agregadas à subcategoria notificação como denúncia demonstram a necessidade de gerar estratégias de construção conjunta de novos entendimentos sobre o problema e de ações para seu enfrentamento.

Como uma primeira etapa de trabalhos do PET-Saúde, esta pesquisa desdobrou-se na proposição de grupos de trabalho com os profissionais interessados em abordar a questão da violência. Além disso, deflagrou um conjunto de articulações para maior compreensão dos equipamentos do município, em outros setores governamentais, que alimentarão os profissionais com a possibilidade de construção de fluxos mais coerentes de intervenção. Visualiza-se que a pesquisa realizada pode contribuir para a implementação de políticas públicas voltadas para estratégias de prevenção da violência contra mulheres e para o aprimoramento das formas de envolvimento dos profissionais da atenção primária à saúde com esse problema. Reitera-se que a violência é um tema de saúde pública, embora seu enfretamento requeira articulações multidisciplinares e intersetoriais. Caminhar nessa direção implica diminuir o abismo entre o consenso discursivo e o dissenso das práticas quando se trata de questões que convocam a intersetorialidade 38 . 


\section{Resumen}

Esta investigación tiene como objetivo mapear indicadores de violencia contra las mujeres en las unidades básicas de Belo Horizonte, Minas Gerais, Brasil, e identificar las dificultades observadas por los profesionales de sanidad en la notificación de la violencia. Datos epidemiológicos sobre ese tipo de notificación fueron recogidos en el sistema de información de la Secretaría Municipal de Salud. Se consiguieron datos cualitativos mediante un cuestionario semiestructurado y tres sesiones de grupos focales, con la participación de 270 profesionales de atención primaria a la salud. Los datos fueron sometidos a un análisis de contenido, fueron codificados, categorizados y discutidos a la luz de la revisión de la literatura. Un eje analítico central fue denominado (in)visibilidad de la violencia contra las mujeres. Emergen dos datos, tanto el reconocimiento de la violencia como un problema de salud pública, como la invisibilidad que impide su enfrentamiento. Se observa que la notificación es frecuentemente entendida como denuncia, lo que dificulta el avance en las discusiones y acciones concernientes al problema.

Notificación; Violencia Contra la Mujer; Personal de Salud; Atención Primaria de Salud

\section{Colaboradores}

L. Kind, M. L. P. Orsini, V. Nepomuceno, L. Gonçalves, G. A. Souza e M. F. F. Ferreira contribuíram em todas as etapas de produção do artigo; concepção, análise e interpretação dos dados, redação do artigo e revisão crítica do conteúdo, e aprovação final da versão a ser publicada.

\section{Agradecimentos}

Aos parceiros do Distrito Sanitário Nordeste pelas importantes interlocuções e às demais colegas de equipe pela colaboração na coleta dos dados e discussões sobre o trabalho. Ao Ministério da Saúde/SGTES e CNPq (Pró-Saúde e PET-Saúde) pelo financiamento.

\section{Referências}

1. Garcia-Moreno C, Jansen HAFM, Elsberg M, Heise L, Watts C. Who multi-country study on women's health and domestic violence against women: initial results on prevalence, health outcomes and women's responses. Geneva: World Health Organization; 2005.

2. Fontana M. Violência contra a mulher. In: Rede Nacional Feminista de Saúde e Direitos Reprodutivos, organizador. Saúde da mulher e direitos reprodutivos: dossiês. São Paulo: RedeSaúde; 2001. p. 101-28.

3. Gomes R, Minayo MCS, Silva CFR. Violência contra a mulher: uma questão transnacional e transcultural das relações de gênero. In: Secretaria de Vigilância em Saúde, Ministério da Saúde, organizador. Impacto da violência na saúde dos brasileiros. Brasília: Ministério da Saúde; 2005. p. 117-40.

4. Schraiber LB, d'Oliveira AFPL. Violência contra mulheres: interfaces com a saúde. Interface Comun Saúde Educ 1999; 3:11-26.
5. Schraiber L, d'Oliveira AFPL. Violência dói e não é direito. São Paulo: Editora Unesp; 2005.

6. Schraiber LB, d'Oliveira AFPL, Couto MT. Violência e saúde: contribuições teóricas, metodológicas e éticas de estudos da violência contra a mulher. Cad Saúde Pública 2009; 25 Suppl 2:S205-16.

7. Oliveira CC, Fonseca RMGS. Práticas dos profissionais das equipes de saúde da família voltadas para as mulheres em situação de violência sexual. Rev Esc Enferm USP 2007; 41:605-12.

8. Pedrosa CM, Spink MJP. A violência contra mulher no cotidiano dos serviços de saúde: desafios para a formação médica. Saúde Soc 2011; 20:124-35.

9. Cavalcanti LF, Gomes R, Minayo MCS. Representações sociais de profissionais de saúde sobre violência sexual contra a mulher: estudo em três maternidades públicas municipais do Rio de Janeiro, Brasil. Cad Saúde Pública 2006; 22:31-9. 
10. De Ferrante FG, Santos MA, Vieira EM. Violência contra a mulher: percepção dos médicos das unidades básicas de saúde da cidade de Ribeirão Preto, São Paulo. Interface Comun Saúde Educ 2009; 13:287-99.

11. Marinheiro ALF, Vieira EM, Souza L. Prevalência da violência contra a mulher usuária de serviço de saúde. Rev Saúde Pública 2006; 40:604-10.

12. Okabe I, Fonseca RMGS. Violência contra a mulher: contribuições e limitações do sistema de informação. Rev Esc Enferm USP 2009; 43:453-8.

13. Santinon EP, Gualda DMR, Silva LCFP. Violência contra a mulher: notificação compulsória e outros instrumentos legais de uso dos profissionais de saúde. Revista Âmbito Jurídico 2010; XIII(74). http:/ / www.ambito-juridico.com.br/pdfsGera dos/artigos/7499.pdf (acessado em 10/Fev/2012).

14. Schraiber LB, Lucas AFPL, Couto MP, Hanada H, Kiss LB, Durand JG, et al. Violência contra mulheres entre usuárias de serviços públicos de saúde da Grande São Paulo. Rev Saúde Pública 2010; 41:359-67.

15. Organização dos Estados Ibero-Americanos para a Educação, a Ciência e a Cultura. Mapa da violência dos municípios brasileiros. Brasília: Ministério da Saúde; 2008.

16. Brasil. Lei no 10.778 , de 24 de novembro de 2003. Diário Oficial da União 2003; 25 nov.

17. Secretaria Especial de Políticas para as Mulheres. Enfrentando a violência contra a mulher. Orientações práticas para profissionais e voluntários(as). Brasília: Secretaria Especial de Políticas para as Mulheres; 2005.

18. Prefeitura de Belo Horizonte. Belo Horizonte ganha plano de enfrentamento à violência contra as mulheres. http://www.jusbrasil.com.br/ politica/4664272/belo-horizonte-ganha-planode-enfrentamento-a-violencia-contra-as-mulhe res (acessado em 24/Abr/2010).

19. Romagnoli R, Martins FFS, organizadores. Violência doméstica: estudos atuais e perspectivas. Curitiba: CRV; 2012.

20. Okuda Benavides M, Gómez-Rastrepo C. Métodos en investigación cualitativa: triangulación. Rev Colomb Psquiatr 2005; 34:118-24.

21. Minayo MCS. O desafio do conhecimento. 12a Ed. São Paulo: Editora Hucitec; 2010.

22. Becker HS. Segredos e truques da pesquisa. Rio de Janeiro: Jorge Zahar Editor; 2007.

23. Turato ER. Métodos qualitativos e quantitativos na área da saúde: definições, diferenças e seus objetos de pesquisa. Rev Saúde Pública 2005; 39:507-14.

24. Flick U. Introdução à pesquisa qualitativa. 3a Ed. Porto Alegre: Editora Artmed; 2009.
25. Kind L. Notas para o trabalho com técnica de grupos focais. Psicol Rev (Belo Horizonte) 2004; 10:124-36.

26. Gibbs G. Análise de dados qualitativos. Porto Alegre: Editora Artmed; 2008.

27. Bardin L. Análise de conteúdo. 5a Ed. Lisboa: Edições 70; 2011

28. Friese S. Qualitative data analysis with ATLAS.ti. London: Sage; 2012.

29. Brasil. Lei no 11.340 , de 7 de agosto de 2006. Diário Oficial da União 2006; 8 ago.

30. Saliba O, Garbin CAS, Garbin AJI, Dossi AP. Responsabilidade do profissional de saúde sobre a notificação de casos de violência doméstica. Rev Saúde Pública 2007; 41:472-7.

31. Luna EJA. O SINAN e o resgate da informação para a vigilância epidemiológica. Epidemiol Serv Saúde 2004; 13:133-4.

32. Ferreira Neto JL, Kind L. Promoção da saúde e práticas grupais na Estratégia Saúde da Família. São Paulo: Editora Hucitec; 2011.

33. Giovanella L, Mendonça MHM. Atenção primária à saúde. In: Giovanella L, Escorel S, Lobato LVC, Noronha JC, Carvalho AI, organizadores. Políticas e sistema de saúde no Brasil. Rio de Janeiro: Editora Fiocruz/Centro Brasileiro de Estudos de Saúde; 2008. p. 575-625.

34. Foucault M. Microfísica do poder. 15a Ed. Rio de Janeiro: Edições Graal; 2002.

35. Foucault M. História da sexualidade I: a vontade de saber. 15a Ed. Rio de Janeiro: Edições Graal; 2003.

36. Oliveira MR, Melo CVF. Saúde, relações de gênero e violência: atendimentos e encaminhamentos na estratégia saúde da família em Cariús/CE. In: III Seminário Nacional Gênero e Práticas Culturais: Olhares Diversos sobre a Diferença. http://itapo ranga.net/genero/3/08/24.pdf (acessado em 03/ Dez/2011).

37. Vieira EM, Perdona GCS, Almeida AM, Nakano MAS, Santos MA, Daltoso D, et al. Knowledge and attitudes of healthcare workers towards gender based violence. Rev Bras Epidemiol 2009; 12:566-77.

38. Mendes R, Akerman M. Intersetorialidade: reflexões e práticas. In: Fernandes JCA, Mendes R, organizadores. Promoção da saúde e gestão local. São Paulo: Editora Hucitec; 2009. p. 85-109.

Recebido em 03/Jul/2012

Versão final reapresentada em 09/Fev/2013

Aprovado em 27/Mar/2013 